\title{
Biometric approach applied to soybean genotypes cultivated in Rio Grande do Sul, Brazil
}

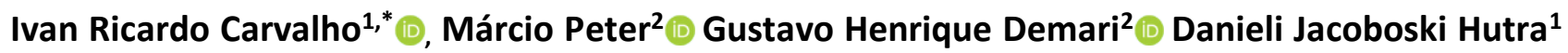 \\ (D) Giordano Gelain Conte ${ }^{2}$ Christian Szambelam Zimmermann ${ }^{1}$ C] José Gonzalez da Silva ${ }^{1}([)$ and \\ Jaqueline Piesanti Sangiovo ${ }^{1}$
}

${ }^{1}$ Universidade Regional do Noroeste do Estado do Rio Grande do Sul (UNIJUí), Ijuí, Brazil. 2Universidade Federal de Pelotas (UFPEL), Rio Grande do Sul, Brazil. *Corresponding author, E-mail: carvalho.irc@gmail.com.

\begin{abstract}
The study had the purpose to evidence the agronomic performance, inter-relations of characters and the multivariate differentiation of soybean genotypes cultivated in the preferential season, in the state of Rio Grande do Sul, Brazil. In the crops season of 2017/2018, The experimental design was the completely randomized blocks, being 25 genotypes with three replicates. The data obtained was submitted to presuppositions based on normality and homogeneity of residual variances, variance analysis, Tocher method, Euclidian algorithm, linear correlations, relative contribution of characters by Singh and artificial neural networks. The agronomic performance of the genotypes presents superior seeds yield per plant through the elevated magnitude of reproductive nodes, legumes and seeds per plant. The plant height of the soybean is positively associated with the number of total nodes and reproductive nodes in the main stem and branches, where they are directly linked with the soybean productive potential. The most polymorphic characters correspond to the number and mass of thousand seeds, being possible to differentiate in a multivariate way the soybean genotypes though the similarity profiles.
\end{abstract}

Keywords Biometric procedures, experimentation multivariate, Glycine max L, phenotypic plasticity, statistical models, selection.

\section{INTRODUCTION}

The soybean crop presents large economic importance, used in the human diet (Empresa Brasileira de Pesquisa Agropecuária [EMBRAPA], 2014), being source of bioactive compounds (Dueñas et al., 2012), as well, as source of protein to animal feed (Cavalett \& Ortega, 2010).In the crop season of 2017/18 the Brazilian production had a total of 118.8 million tons and yield of 3.3 thousand kilograms of grains per hectare. In Rio Grande do Sul, it were produced 17 million tons of grains cultivated in 5.6 million hectares, it was result of a productivity superior to three tons per hectare (Companhia Nacional de Abastecimento [CONAB], 2018).

The yield can be influenced by several factors that affect the growth and development of the crop, such as, cycle length or relative group maturity, plant population, magnitude of reproductive structures (flowers, legumes and seeds) per plant as well seeds mass (Carvalho et al., 2016, 2017). The variability of these compounds is dependable of actions imposed by the environment where the genotypes are grown, being crucial to evidence the phenotypic plasticity that the different genetic constitutions express (Komori, Hamawaki, Souza, \& Shigihara 2004).

Plenty of new soybean cultivars are annually being put available, it determines the necessity to comprehend the productive performance and the modifications of the morphologic attributes, in this manner, the technologies and management alternatives allow to increment in $20,5 \%$ the yield per area between 2007 and 2017 (CONAB, 2018). It was possible through the correct recommendations of cultivars to specific environments and due to genetic breeding, assisting the obtaining of superior genotypes related to the maximum exploitation of natural resources and anthropic actions, being converted to yield (Szareski et. al., 2018; Carvalho et. al., 2016;).

The identification of which are the main characters of agronomic importance can be realized by the employment of biometric procedures, among them, can be used the optimized grouping methods, based on the homogeneity and heterogeneity among groups (Cruz, 2014). As well, can be used the 
comprehension of linear tendencies among these characters, definition of genetic dissimilarities and graphic constructions that allow the maximum explanation among the genotypes, similarly use computational insights to define genotype profiles using all the experimental information available (Carvalho et al., 2018). In this context, this study had the purpose to evidence the agronomic performance, inter-relations of characters and the multivariate differentiation of soybean genotypes cultivated in the preferential season, in the state of Rio Grande do Sul.

\section{MATERIALS AND METHODS}

The experiment was carried out in the city of Tenente Portela, RS, in the crops season of $2017 / 18$, in the coordinates of $277^{\circ} 22^{\prime} 10,20^{\prime \prime} \mathrm{S}$ and longitude $53 \circ 45^{\prime} 23,00$ "W, with altitude of 420 meters. The soil is classified as dystrophic red latosol (Streck et al., 2008), and the climate in characterized as subtropical type $\mathrm{Cfa}$. The experimental design was the completely randomized blocks, being 25 genotypes with three replicates. The experimental units were composed of four lines spaced by 0.45 meters and five meters length.

The manual sowing was based on the population density of 250 thousand plants per hectare, with base fertilizing of $300 \mathrm{~kg}$ ha ${ }^{-1} \mathrm{~N}-\mathrm{P}-\mathrm{K}$ in the formulation 02-20-20. It was effected a preventive disease control management to minimize the biotic effects in this study. The genotypes used were selected based on those commonly used in the state, being: NS 5909 RG, BMX Turbo RR, BMX Alvo RR, BMX Magna RR, BMX Força RR, BMX Tornado RR, 6863 RSF, BMX Ativa RR, TMG 7262 RR, FPS Urano RR, FPS Júpiter RR, FPS Antares RR, DOW 5D615 RR, Monsoy 5410 IPRO, Monsoy 6410 IPRO, NS 5445 IPRO, NS 6700 IPRO, NS 5959 IPRO, TMG 7062 IPRO, TMG 7063 IPRO, AS 3610 IPRO, DM 5958 IPRO, AS 3575 IPRO, Monsoy 5882 IPRO, BMX Elite IPRO and TEC 6029 IPRO.

The characters were measured in 10 plants randomly selected, in the utile area of each experimental unit, being: plant height $(\mathrm{PH}, \mathrm{cm})$, height of the first legume insertion (HFLI, $\mathrm{cm})$, number of nodes in the main stem (NNMS, units), number of reproductive nodes in the main stem (NRNMS, units), number of legumes in the main stem (NLMS, unit), number of legumes per node in the main stem (NLNMS, unit), number of branches (NB, unit), number of legumes per branch (NLB, unit), number of legumes per node in the branches (NLNB, unit), branches length (BL, cm), number of reproductive nodes in the branch (NRNB, unit), number of legumes containing one seed (NL1S, unit), two seeds (NL2S), three seeds (NL3S, unit) and four seeds (NL4S, unit), total number of legumes per plant (TNL, unit), total number of seeds per plant (TNS, unit), mass of seeds from legumes with one, two, three and four seeds (MS1, MS2, MS3 and MS4), mass of seeds per plant (MSP, grams) and mass of thousand seeds stratified to the magnitude of seeds per legume (MTS1, MTS2, MTS3 and MTS4, grams).

The data obtained was submitted to presuppositions based on normality and homogeneity of residual variances. Afterwards, the characters were submitted to variance analysis of $5 \%$ probability by $\mathrm{F}$ test, being executed the Tocher method of optimized grouping, based on the patterned Euclidian algorithm, linear correlations, genetic dissimilarities and grouping by the grouping method of non-pondered pair with arithmetic mean (UPGMA), relative contribution of characters by Singh (1981) and artificial neural networks through the Kohonen map using computational non-supervised learning.

\section{RESULTS AND DISCUSSION}

The variance analysis (Table 1) revealed significance at $5 \%$ probability, evidencing that the 25 soybean genotypes differs to PH, HFLI, NNMS, NRNMS, NLNMS, NB, NLB, NLNB, NL1S, NL2S, NL3S, NL4S, TNL, TNS, MS1, MS2, M23, M24, MSP and MTS1, MTS2, MTS3, MTS4. The Tocher optimized grouping method is based on the lower dissimilarity within the groups or similarities intra-groups, as well, higher univariate dissimilarities between groups for the interest characters (Vasconcelos, Cruz, Bhering, \& Resende-Júnior, 2007) (Table 2).The PH evidenced being close to the ideal sought in the selection through the group $C$ formed by the genotypes NS 6700 IPRO, DM 5958 IPRO, FPS Antares RR, M5882 IPRO and NS 5959 IPRO, with the average height of $116 \mathrm{~cm}$, however, thus, also, evidences were revealed by the group $\mathrm{F}$ through the genotypes with determined growth habit FPS Urano RR e BMX Ativa RR. According studies of Sediyama (2016), it sought plants close to $80 \mathrm{~cm}$ of height.

The HFLI oscillated from 13.4 to $37.1 \mathrm{~cm}$, where $72 \%$ of the studied genotypes are within the group A, where the intra-group average was $18.9 \mathrm{~cm}$. This attribute is indispensable to the practices of mechanized harvest, hence, it is sought genotypes with at least $10 \mathrm{~cm}$, in order to be possible to maximize the magnitude Agronomy Science and Biotechnology, Rec. 118, Volume 7, Pages 1-10, 2021 
of reproductive node in the soybean branches (Sediyama, 2016). Researches point out that this attribute can be influenced by edapho-climatic factors, plants array and characteristics of the genotypes (Carvalho et al., 2017). The NNMS define that the group A was composed of $24 \%$ of the genotypes, revealing 4.8 nodes responsible for the morphologic structures. In relation to the NRNMS, the groups $A, B$ and $C$ were superiorwith 11.2, 13.2 and 15.3 nodes responsible for reproductive structures, in this manner, stands out the genotypes FPS Antares RR and BMX Ativa RR with 8.7 and 10.6 reproductive nodes.

Table 1. Summary of the variance analysis to 25 soybean genotypes.

\begin{tabular}{|c|c|c|c|c|c|c|c|c|}
\hline \multicolumn{9}{|c|}{ Variance components } \\
\hline & DF & $\mathrm{PH}$ & HFLI & NNMS & NRNMS & NLMS & NLNMS & NB \\
\hline Genotypes & 24 & $9081.5^{*}$ & $952.93^{*}$ & $33.85^{*}$ & 139.60* & $1227.50^{*}$ & $6.36^{*}$ & $37.86^{*}$ \\
\hline Blocks & 2 & 357.26 & 182.34 & 17.11 & 11.80 & 85.46 & 1.45 & 26.62 \\
\hline Residue & 673 & 78.63 & 34.15 & 2.33 & 5.72 & 67.40 & 0.34 & 2.45 \\
\hline \multicolumn{9}{|c|}{ Variance components } \\
\hline & DF & NLNB & NL4S & MS4 & NRNB & NLB & $\mathrm{BL}$ & NL1S \\
\hline Genotypes & 24 & $2.25^{*}$ & $1.81^{*}$ & $0.46^{*}$ & $1140.45^{*}$ & $3249.11^{*}$ & $2663.30^{*}$ & $124.55^{*}$ \\
\hline Blocks & 2 & 2.12 & 0.13 & 0.08 & 597.73 & 2191.12 & 63.99 & 6.32 \\
\hline Residue & 673 & 0.41 & 0.42 & 0.13 & 89.40 & 288.10 & 181.51 & 14.81 \\
\hline \multicolumn{9}{|c|}{ Variance components } \\
\hline & DF & NL2S & NL3S & TLN & TNS & MS1 & MS2 & MS3 \\
\hline Genotypes & 24 & $1636.08^{*}$ & $1188.01^{*}$ & $4863.63^{*}$ & $13638.02^{*}$ & $1.84^{*}$ & $75.69 *$ & $287.84 *$ \\
\hline Blocks & 2 & 594.31 & 318.51 & 2008.84 & 3484.99 & 0.19 & 31.01 & 23.68 \\
\hline Residue & 673 & 122.17 & 119.31 & 484.11 & 1210.73 & 0.36 & 7.25 & 34.73 \\
\hline \multicolumn{9}{|c|}{ Variance components } \\
\hline & & DF & MSP & MTS1 & MTS2 & MTS3 & MTS4 & \\
\hline & Genotypes & 24 & $596.40^{*}$ & $14724.62 *$ & 13696.40* & $13942.24^{*}$ & $12132.27^{*}$ & \\
\hline & Blocks & 2 & 161.89 & 3621.93 & 2026.43 & 311.41 & 1595.62 & \\
\hline & Residue & 673 & 73.52 & 882.34 & 459.28 & 363.80 & 3039.38 & \\
\hline
\end{tabular}

*significant at 5\%. DF: degrees of freedom.

Plant height $(\mathrm{PH}, \mathrm{cm})$, height of the first legume insertion (HFLI, $\mathrm{cm})$, number of nodes in the main stem (NNMS, units), number of reproductive nodes in the main stem (NRNMS, units), number of legumes in the main stem (NLMS, unit), number of legumes per node in the main stem (NLNMS, unit), number of branches (NB, unit), number of legumes per branch (NLB, unit), number of legumes per node in the branches (NLNB, unit), branches length (BL, cm), number of reproductive nodes in the branch (NRNB, unit), number of legumes containing one seed (NL1S, unit), two seeds (NL2S), three seeds (NL3S, unit) and four seeds (NL4S, unit), total number of legumes per plant (TNL, unit), total number of seeds per plant (TNS, unit), mass of seeds from legumes with one, two, three and four seeds (MS1, MS2, MS3 and MS4), mass of seeds per plant (MSP, grams) and mass of thousand seeds stratified to the magnitude of seeds per legume (MTS1, MTS2, MTS3 and MTS4, grams). 
Table 2. Optimized Tocher grouping for 25 soybean genotypes.

\begin{tabular}{|c|c|c|c|c|c|c|c|c|c|c|c|c|c|c|c|c|c|c|c|c|c|c|c|c|c|c|c|}
\hline Gen & nótipos & $\stackrel{*}{T}$ & 咅 & $\sum_{z}^{n}$ & $\sum_{\sum}^{n}$ & $\sum_{z}^{n}$ & $\sum_{\sum}^{n}$ & $\underline{\mathbf{m}}$ & $\sum_{\substack{\alpha \\
z}}^{\infty}$ & $\stackrel{\varphi}{z}$ & $\underset{z}{\underline{z}}$ & $\overrightarrow{\boldsymbol{\omega}}$ & $\stackrel{n}{z}$ & $\underset{\mathcal{Z}}{z}$ & $\stackrel{\tilde{m}}{z}$ & $\stackrel{y}{z}$ & $\stackrel{\varrho}{\sum}$ & जे & $\sum_{\Sigma}^{n}$ & $\tilde{N}$ & $\stackrel{n}{n}_{\Sigma}^{n}$ & 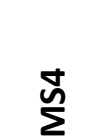 & $\stackrel{n}{\Sigma}$ & $\stackrel{\vec{n}}{\Sigma}$ & $\underset{\Sigma}{\stackrel{N}{\Sigma}}$ & $\stackrel{n}{\stackrel{n}{\Sigma}}$ & $\frac{H}{\Sigma}$ \\
\hline 1 & AS 3575 IPRO & $A$ & $A$ & $\mathrm{D}$ & B & $A$ & $A$ & $\mathrm{~F}$ & $A$ & $A$ & $B$ & $B$ & $B$ & $B$ & $A$ & $A$ & $A$ & $A$ & $B$ & $A$ & $A$ & $A$ & $A$ & $B$ & $\mathrm{D}$ & $B$ & $A$ \\
\hline 2 & AS 3610 IPRO & $A$ & B & $\mathrm{C}$ & $A$ & $A$ & B & $\mathrm{D}$ & $A$ & $A$ & $A$ & B & B & B & $A$ & B & $A$ & $A$ & $A$ & $A$ & $A$ & $\mathrm{D}$ & $A$ & $\mathrm{H}$ & $D$ & B & $D$ \\
\hline 3 & NS 6700 IPRO & $\mathrm{C}$ & $\mathrm{C}$ & $\mathrm{H}$ & B & $A$ & $A$ & $A$ & $A$ & $A$ & $\mathrm{C}$ & $A$ & B & B & $A$ & $A$ & $A$ & $A$ & $\mathrm{C}$ & $A$ & $A$ & $E$ & $A$ & $\mathrm{~F}$ & $\mathrm{~F}$ & $D$ & $A$ \\
\hline 4 & BMX Alvo RR & $\mathrm{E}$ & $A$ & 1 & $\mathrm{C}$ & $A$ & $A$ & $A$ & $A$ & $A$ & $A$ & $A$ & B & $A$ & B & B & $A$ & B & $A$ & $A$ & $A$ & $D$ & $A$ & $E$ & B & $A$ & $E$ \\
\hline 5 & BMX Força RR & $A$ & $A$ & D & $\mathrm{D}$ & $\mathrm{C}$ & $A$ & B & $A$ & $A$ & $A$ & $\mathrm{C}$ & $A$ & $\mathrm{D}$ & $\mathrm{B}$ & $\mathrm{B}$ & $\mathrm{B}$ & $D$ & $A$ & $A$ & $A$ & $A$ & $A$ & $A$ & $A$ & $\mathrm{C}$ & $A$ \\
\hline 6 & BMX Magna RR & $\mathrm{B}$ & $A$ & $A$ & $\mathrm{C}$ & $A$ & $A$ & $\mathrm{C}$ & B & B & $A$ & $A$ & $\mathrm{C}$ & $E$ & $A$ & $A$ & B & B & $A$ & B & $A$ & $A$ & $A$ & $A$ & $A$ & $\mathrm{C}$ & B \\
\hline 7 & BMX Tornado RR & B & $A$ & 1 & $\mathrm{C}$ & $A$ & $A$ & $A$ & $A$ & $A$ & $A$ & $\mathrm{C}$ & $\mathrm{C}$ & $A$ & $A$ & $A$ & $A$ & B & $A$ & $A$ & $A$ & $\mathrm{C}$ & $A$ & $\mathrm{D}$ & B & $A$ & B \\
\hline 8 & DM 5958 IPRO & $\mathrm{C}$ & $\mathrm{B}$ & B & $A$ & $\mathrm{~B}$ & $A$ & $\mathrm{C}$ & $A$ & $A$ & $A$ & $A$ & B & B & $A$ & $A$ & $A$ & $A$ & $A$ & $A$ & $A$ & B & $A$ & B & $\mathrm{D}$ & $A$ & $\mathrm{C}$ \\
\hline 9 & DOW 5D615 RR & B & $A$ & $\mathrm{~F}$ & $\mathrm{D}$ & $A$ & $A$ & $E$ & $\mathrm{C}$ & $\mathrm{C}$ & $A$ & $\mathrm{C}$ & $\mathrm{D}$ & $\mathrm{C}$ & $\mathrm{C}$ & $\mathrm{C}$ & $\mathrm{C}$ & $\mathrm{D}$ & $\mathrm{D}$ & $\mathrm{C}$ & B & $\mathrm{F}$ & B & $\mathrm{D}$ & B & $A$ & $E$ \\
\hline 10 & FPS Antares RR & $\mathrm{C}$ & $A$ & $\mathrm{D}$ & $E$ & $\mathrm{C}$ & $A$ & $A$ & $A$ & $A$ & B & $A$ & $\mathrm{C}$ & D & $A$ & B & $A$ & B & $A$ & $A$ & $A$ & $A$ & $A$ & $A$ & $A$ & $\mathrm{C}$ & $\mathrm{F}$ \\
\hline 11 & FPS Jupter RR & B & $A$ & $J$ & $\mathrm{C}$ & $A$ & $A$ & B & B & $A$ & $A$ & $\mathrm{C}$ & B & $\mathrm{D}$ & $A$ & $\mathrm{C}$ & $A$ & B & $A$ & $A$ & $A$ & $\mathrm{~F}$ & $A$ & $\mathrm{C}$ & $A$ & $\mathrm{C}$ & $\mathrm{D}$ \\
\hline 12 & FPS Urano RR & $\mathrm{F}$ & $A$ & $\mathrm{~F}$ & $A$ & $A$ & B & $A$ & $A$ & $A$ & $A$ & $A$ & $A$ & $\mathrm{C}$ & $A$ & $A$ & $A$ & $A$ & $\mathrm{C}$ & B & $A$ & B & $A$ & $\mathrm{C}$ & $A$ & $\mathrm{C}$ & $\mathrm{C}$ \\
\hline 13 & M 5882 IPRO & $\mathrm{C}$ & B & B & $A$ & $\mathrm{~B}$ & $A$ & $\mathrm{C}$ & $A$ & $A$ & $A$ & $A$ & B & B & $A$ & $A$ & $A$ & $A$ & B & $A$ & $A$ & B & $A$ & $A$ & $A$ & $\mathrm{C}$ & G \\
\hline 14 & M 5410 IPRO & $A$ & $A$ & $\mathrm{D}$ & $A$ & $A$ & B & B & $A$ & $A$ & $A$ & $A$ & $\mathrm{C}$ & $A$ & B & $A$ & $A$ & B & $A$ & $A$ & $A$ & B & $A$ & $A$ & $A$ & $\mathrm{C}$ & B \\
\hline 15 & BMX Ativa RR & $\mathrm{F}$ & $A$ & G & $A$ & $A$ & $\mathrm{C}$ & $\mathrm{D}$ & $A$ & $A$ & $A$ & B & $\mathrm{C}$ & $\mathrm{D}$ & $A$ & $A$ & $A$ & $\mathrm{C}$ & $\mathrm{C}$ & B & $A$ & B & $A$ & I & B & $A$ & $\mathrm{C}$ \\
\hline 16 & BMX Elite IPRO & B & $A$ & $A$ & B & $A$ & $A$ & $A$ & $A$ & $A$ & $A$ & $A$ & $A$ & $A$ & $A$ & $A$ & $A$ & $\mathrm{C}$ & $\mathrm{C}$ & B & $A$ & $\mathrm{C}$ & $A$ & B & $\mathrm{D}$ & $A$ & B \\
\hline 17 & M 6410 IPRO & $A$ & $A$ & $A$ & B & $A$ & $A$ & $\mathrm{C}$ & $A$ & $A$ & $A$ & $A$ & B & $A$ & B & $A$ & $A$ & B & B & $A$ & $A$ & B & $A$ & $A$ & $A$ & $\mathrm{C}$ & $\mathrm{C}$ \\
\hline 18 & NA 5909 RG & $E$ & $A$ & G & $\mathrm{C}$ & $A$ & $A$ & $E$ & B & B & $A$ & $\mathrm{C}$ & $A$ & $\mathrm{D}$ & B & $A$ & B & B & $\mathrm{C}$ & B & $A$ & $\mathrm{C}$ & $A$ & B & B & $A$ & $\mathrm{C}$ \\
\hline 19 & NS 5445 IPRO & $A$ & $A$ & C & $A$ & $A$ & $A$ & B & $A$ & $A$ & $E$ & $A$ & B & B & $A$ & $A$ & $A$ & $A$ & $A$ & $A$ & $A$ & $E$ & $A$ & G & $\mathrm{C}$ & B & $E$ \\
\hline 20 & NS 5959 IPRO & $\mathrm{C}$ & B & $E$ & B & $\mathrm{B}$ & $A$ & B & $A$ & $A$ & $A$ & $A$ & B & B & $A$ & $A$ & $A$ & $A$ & $A$ & $\mathrm{D}$ & $A$ & $\mathrm{C}$ & $A$ & $E$ & $E$ & $\mathrm{C}$ & B \\
\hline 21 & TEC 6029 IPRO & B & $A$ & $A$ & B & $A$ & $A$ & $A$ & $A$ & $A$ & $A$ & $A$ & B & $A$ & $A$ & $A$ & $A$ & $\mathrm{C}$ & $A$ & $A$ & $A$ & $\mathrm{H}$ & $A$ & G & $\mathrm{C}$ & B & $\mathrm{F}$ \\
\hline 22 & TMG 7262 RR & $\mathrm{D}$ & B & $\mathrm{H}$ & $\mathrm{C}$ & $A$ & $A$ & $\mathrm{D}$ & $A$ & $A$ & B & $A$ & B & $A$ & $A$ & $A$ & $A$ & $\mathrm{C}$ & $A$ & B & $A$ & $A$ & $A$ & $\mathrm{~F}$ & $\mathrm{C}$ & $\mathrm{D}$ & B \\
\hline 23 & TMG 7062 IPRO & $\mathrm{D}$ & B & $E$ & B & $A$ & $A$ & $\mathrm{C}$ & $A$ & $A$ & $A$ & $A$ & $A$ & $A$ & $A$ & B & $A$ & $\mathrm{C}$ & $\mathrm{C}$ & $A$ & $A$ & $\mathrm{D}$ & $A$ & $\mathrm{D}$ & B & $A$ & $\mathrm{D}$ \\
\hline 24 & TMG 7063 IPRO & $A$ & $A$ & $A$ & $\mathrm{C}$ & $A$ & $A$ & $\mathrm{D}$ & $A$ & $A$ & B & $A$ & B & B & B & B & $A$ & B & B & $A$ & $A$ & $\mathrm{D}$ & $A$ & $\mathrm{D}$ & B & $A$ & $\mathrm{D}$ \\
\hline 25 & BMX Turbo RR & $A$ & $A$ & $A$ & $A$ & $A$ & $A$ & $\mathrm{~F}$ & $A$ & $\mathrm{D}$ & $\mathrm{D}$ & $\mathrm{D}$ & $\mathrm{B}$ & B & $A$ & B & $A$ & $A$ & $A$ & $A$ & $A$ & G & $A$ & $\mathrm{H}$ & $D$ & B & $D$ \\
\hline
\end{tabular}

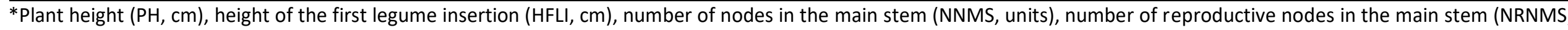

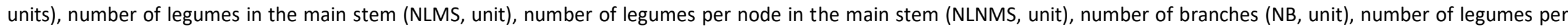

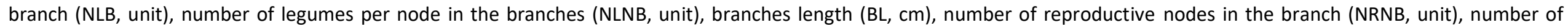

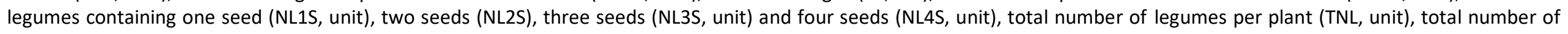

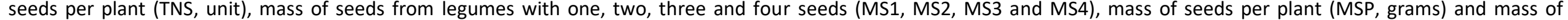
thousand seeds stratified to the magnitude of seeds per legume (MTS1, MTS2, MTS3 and MTS4, grams). 
The NLMS determined that $80 \%$ of the evaluated genotypes have around 35.8 legumes. Superiority for this attribute was expressed for the genotype FPS Antares RR. For the number of legumes per node (group A), where the superiority was obtained through the genotype BMX Ativa RR with 3.9 legumes per node in the main stem. The NB revealed high variability, where lower evidences were obtained through the genotypes AS 3575 IPRO and BMX Turbo RR, although, for DOW 5D615 RR and NA 5909 RG it was obtained averages of 4.7 branches per plant. The magnitude of NRNB infers that in $84 \%$ of genotypes obtained 7.8 nodes per branch, being the genotype DOW 5 D615 superior with 30.4 reproductive units in the lateral branches of the plant. For the NLB it was verified superiority to the genotype DOW 5D615 with 50.1 legumes in the branches. The branches length (BL) evidenced that $64 \%$ of the genotypes obtained average of $27.6 \mathrm{~cm}$, being the group C composed by $20 \%$ of the genotypes and average of $43.2 \mathrm{~cm}$, being superior to the rest.

The magnitude of NL1S was superior for the genotype DOW 5D615 RR with 10.7 legumes. For NL2S better performances were obtained with the genotypes DOW 5D615 RR and NS 5959 IPRO, with 12.5 to 36.8 legumes. NL3S revealed that $68 \%$ of the genotypes answer similarly and are located in the group $A$. In this manner, higher magnitudes were obtained for DOW 5D615 and NS 5445 IPRO, with 16.3 to 42 legumes. NL4S evidenced lower variability. The NL per plant revealed that $84 \%$ of the tested genotypes are located in group A, but higher performances are obtained in the group B, with 69.9 legumes. The TNS express high variability, being the group $D$ responsible for $8 \%$ of the genotypes and average of 160.8 seeds per plant obtained through the prominence of the genotype DOW 5D65 RR.

The mass of seeds stratified due to the legumes characteristics, define that for MS1 the groups D and C are superior. For MS2 higher evidences correspond to the groups $C$ and D with 9.8 and 7.3 grams. For MS3 the group A gathered $96 \%$ of the genotypes with 9.8 grams of average. For both scenarios the genotype DOW 5D615 RR was superior to the rest. The MSP reveals that $96 \%$ of the genotypes expressed average of 16.2 grams to the group A, highlighting the genotype DOW 5D615 and NS 5959 IPRO as superiors. The mass of seeds can be directly influenced by the genetic characteristics, climatic oscillations during the reproductive period specifically in the more advanced reproductive stages and biotic stresses in similar periods (Bruin \& Pedersen, 2008; Balbinot-Junior, Procópio, Debiasi, Franchini, \& Panison 2015; Thompson et al., 2015).

In relation to the MTS1 (one seed) it was obtained superiority to the group F composed by $8 \%$ of the genotypes and 166.1 grams. The MTS2 and MTS3 were more evidenced in the groups A, B and D. In these conditions, prominences were revealed through the genotype NS 6700 IPRO. The PH (Table 3) is positively associated with HFLI and NNMS, as well, HFLI is related to NNMS. In this manner, taller plants allow elevated magnitude of nodes in the main stem, being it possible due to the reduction of the length of internodes.

The magnitude of reproductive nodes in the main stem is associated with NLMS and NB, as well as, BL, NL and NSP are associated with its mass. Studies point out that the increment of nodes in the main stem may determine the increase of reproductive structures as flowers, legumes and seeds, since $66 \%$ of the total legumes per plant can be originated of the main stem (Szareski et al., 2015). The NLMS is correlated with the magnitude of NLNMS, NL2S, NL and NSP. The ramifications are determined by the number of reproductive nodes and legumes per ramification, as well as its length. To Szareski et al. (2015), the magnitudes of branches in soybean plants are intimately linked to its dimensions, it directly influence the legumes with one and two seeds and, consequently, the yield.

The NRNB determines the amount of legumes formed in these structures, also, are related to the dimensions of these ramifications that enhance not only the magnitude of legumes, but also the mass of the seeds. Szareski et al. (2015) state that the increment of length of the branches can enhance the number of reproductive nodes per plant and, as follows, the reproductive structures, where this set of attributes directly increase the soybean production. The magnitude of legumes stratified due to the number of seeds is directly associated with the total of seeds produced per plant, this relation affects no only the amount of seeds but also its mass. Therefore, the superiority of these attributes favors the yield per plant and area unit.

For the grouping using the genetic dissimilarity (Figure 1), higher distances were expressed between the genotype DOW 5D615 RR and the rest, high similarities exist between the genotypes BMX Tornado RR e BMX Magna RR. However, holistically, there is the formation of six large groups. The group I corresponds to the genotype DOW 5D615 RR, being this group established due to this genetic constitution enhance the magnitude of reproductive structures. The group II relate to the genotypes FPS Urano RR and BMX Ativa RR, 
Table 3. Genetic correlation for 25 soybean genotypes considering 26 attributes of agronomic interest.

\begin{tabular}{|c|c|c|c|c|c|c|c|c|c|c|c|c|c|c|c|c|c|c|c|c|c|c|c|}
\hline & NNMS & 0.52 & & NLMS & 0.57 & & NRNMS & -0.29 & & NLNMS & 0.55 & & NRNB & 0.78 & & NLB & 0.95 & & IPL & 0.53 & & NLNR & 0.44 \\
\hline & NRNMS & -0.30 & & NLNMS & -0.27 & & NLMS & -0.10 & & NRNB & 0.17 & & NLB & 0.74 & & NLNR & 0.35 & & NNMS & 0.54 & & BL & 0.61 \\
\hline & NLMS & -0.33 & & NB & 0.42 & & NLNMS & 0.10 & & NLB & 0.17 & & NLNR & 0.48 & & $\mathrm{BL}$ & 0.62 & & NLNMS & -0.15 & & NL1S & 0.57 \\
\hline & NLNMS & -0.12 & & NRNB & 0.50 & & NB & -0.34 & & $\mathrm{BL}$ & 0.22 & & BL & 0.55 & & NL1S & 0.57 & & NRNB & -0.18 & & NL2S & 0.78 \\
\hline & NB & -0.13 & & NLB & 0.47 & & NRNB & -0.44 & & NL1S & 0.32 & & NL1S & 0.43 & & NL2S & 0.75 & & NLB & -0.20 & & NL3S & 0.74 \\
\hline & NRNB & -0.31 & & NLNR & 0.11 & & NLB & -0.44 & & NL2S & 0.50 & & NL2S & 0.54 & & NL3S & 0.73 & & NLNR & -0.07 & & NL4S & 0.18 \\
\hline & NLB & -0.32 & & $\mathrm{BL}$ & 0.55 & & NLNR & -0.17 & & NL3S & 0.47 & & NL3S & 0.47 & & NL4S & 0.18 & & NL1S & -0.18 & & NLP & 0.88 \\
\hline & BL & -0.23 & & NL1S & 0.33 & & BL & -0.32 & & NL4S & 0.17 & & NL4S & 0.12 & 刍 & NLP & 0.86 & & NL2S & -0.30 & & NSP & 0.76 \\
\hline & NL1S & -0.27 & & NL2S & 0.54 & $\boldsymbol{\Omega}$ & NL1S & -0.29 & $\sum^{\infty}$ & NLP & 0.54 & $\ddot{z}$ & NLP & 0.57 & 先 & NSP & 0.73 & $a$ & NLP & -0.19 & Z & MS1 & 0.36 \\
\hline & NL2S & -0.42 & $\mathscr{\Omega}$ & NL3S & 0.59 & $\sum$ & NL2S & -0.43 & 公 & NSP & 0.57 & & NSP & 0.46 & & MS1 & 0.39 & & NSP & -0.10 & & MS2 & 0.69 \\
\hline E & NL3S & -0.29 & 言 & NL4S & 0.23 & 乙 & NL3S & -0.30 & & MS1 & 0.26 & & MS1 & 0.29 & & MS2 & 0.68 & & MS1 & -0.10 & & MS3 & 0.69 \\
\hline & NL4S & -0.10 & $\frac{\pi}{7}$ & NLP & 0.60 & & NLP & -0.42 & & MS2 & 0.47 & & MS2 & 0.48 & & MS3 & 0.74 & & MS2 & -0.24 & & MS4 & 0.16 \\
\hline & NLP & -0.40 & & NSP & 0.63 & & NSP & -0.34 & & MS3 & 0.40 & & MS3 & 0.45 & & MS4 & 0.15 & & MST & -0.10 & & MST & 0.79 \\
\hline & NSP & -0.36 & & MS1 & 0.24 & & MS1 & -0.18 & & MS4 & 0.17 & & MS4 & 0.09 & & MST & 0.81 & & MTS1 & 0.10 & & MTS1 & -0.16 \\
\hline & MS1 & -0.15 & & MS2 & 0.49 & & MS2 & -0.37 & & MST & 0.46 & & MST & 0.52 & & MTS1 & -0.15 & & MTS2 & 0.18 & & MTS2 & -0.21 \\
\hline & MS2 & -0.35 & & MS3 & 0.50 & & MS3 & -0.26 & & MTS1 & -0.08 & & MTS1 & -0.14 & & MTS2 & -0.20 & & MTS3 & 0.17 & & MTS3 & -0.18 \\
\hline & MS3 & -0.24 & & MS4 & 0.22 & & MST & -0.34 & & MTS2 & -0.09 & & MTS2 & -0.19 & & MTS3 & -0.16 & & MTS4 & 0.07 & & & \\
\hline & MS4 & -0.08 & & MST & 0.56 & & MTS1 & 0.11 & & MTS3 & -0.08 & & MTS3 & -0.18 & & & & & & & & MS2 & 0.53 \\
\hline & MST & -0.31 & & MTS1 & -0.13 & & MTS2 & 0.19 & & MTS4 & 0.13 & & & & & NL4S & 0.21 & & NB & -0.41 & & MS3 & 0.37 \\
\hline & MTS1 & 0.14 & & MTS2 & -0.14 & & MTS3 & 0.17 & & & & & NL3S & 0.51 & & NLP & 0.86 & & NRNB & -0.25 & 7 & MS4 & 0.13 \\
\hline & MTS2 & 0.21 & & MTS3 & -0.11 & & & & & NL2S & 0.59 & & NL4S & 0.16 & & NSP & 0.89 & $\sum^{\infty}$ & NLB & -0.21 & $\sum^{\infty}$ & MST & 0.49 \\
\hline & MTS3 & 0.20 & & MTS4 & 0.14 & & NL1S & 0.42 & & NL3S & 0.31 & & NLP & 0.87 & & MS1 & 0.13 & $\mathbf{Z}$ & NLNR & -0.08 & & MTS1 & 0.27 \\
\hline & & & & & & & NL2S & 0.48 & & NL4S & 0.09 & & NSP & 0.71 & & MS2 & 0.45 & $\overline{\mathbf{Z}}$ & BL & -0.22 & & MTS2 & 0.12 \\
\hline & NSP & 0.98 & & BL & 0.55 & & NL3S & 0.55 & & NLP & 0.62 & & MS1 & 0.41 & 3 & MS3 & 0.92 & & NSP & 0.09 & & MTS3 & 0.12 \\
\hline & MS1 & 0.40 & & NL1S & 0.31 & & NL4S & 0.18 & & NSP & 0.39 & กี & MS2 & 0.89 & $\overline{\mathbf{Z}}$ & MS4 & 0.19 & & MS2 & 0.10 & & & \\
\hline & MS2 & 0.79 & & NL2S & 0.33 & & NLP & 0.58 & 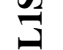 & MS1 & 0.82 & $\overline{\mathbf{Z}}$ & MS3 & 0.57 & & MST & 0.84 & & & & & NLP & 0.23 \\
\hline & MS3 & 0.80 & & NL3S & 0.26 & & NSP & 0.61 & Z & MS2 & 0.58 & & MS4 & 0.15 & & MTS1 & -0.18 & & MS1 & 0.21 & & NSP & 0.15 \\
\hline$\hat{3}$ & MS4 & 0.22 & & NL4S & 0.07 & 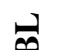 & MS1 & 0.29 & & MS3 & 0.43 & & MST & 0.76 & & MTS2 & -0.16 & & MS2 & 0.57 & & MS1 & 0.10 \\
\hline & MST & 0.90 & 光 & NLP & 0.34 & & MS2 & 0.43 & & MS4 & 0.09 & & MTS1 & -0.15 & & MTS3 & -0.18 & & MS3 & 0.76 & f & MS2 & 0.20 \\
\hline & MTS1 & -0.15 & 3 & NSP & 0.29 & & MS3 & 0.47 & & MST & 0.56 & & MTS2 & -0.24 & & MTS4 & 0.13 & $\theta$ & MS4 & 0.12 & $\bar{Z}$ & MS3 & 0.34 \\
\hline & MTS2 & -0.20 & & MS1 & 0.24 & & MS4 & 0.15 & & MTS2 & -0.09 & & MTS3 & -0.17 & & & & $\bar{Z}$ & MST & 0.82 & & MS4 & 0.95 \\
\hline & MTS3 & -0.17 & & MS2 & 0.31 & & MST & 0.51 & & MTS3 & -0.10 & & & & & & & & MTS1 & -0.15 & & MST & 0.34 \\
\hline & MTS4 & 0.10 & & MS3 & 0.25 & & MTS1 & -0.13 & & & & & & & & MS4 & 0.36 & & MTS2 & -0.20 & & MTS4 & 0.81 \\
\hline & & & & MST & 0.31 & & MTS2 & -0.18 & 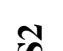 & MS3 & 0.63 & $\bar{D}$ & MTS2 & 0.61 & $\tilde{\Omega}$ & MST & 0.96 & & MTS3 & -0.23 & & & \\
\hline & & & & MTS2 & -0.08 & & MTS3 & -0.18 & $\sum^{\infty}$ & MS4 & 0.22 & $\sum$ & MTS3 & 0.64 & $\Sigma$ & MTS3 & 0.09 & & MTS4 & 0.08 & $\sqrt{2}$ & MTS3 & 0.11 \\
\hline 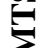 & MTS3 & 0.73 & & MTS3 & -0.09 & & & & & MST & 0.82 & & & & & MTS4 & 0.19 & & & & $\Sigma$ & MTS4 & 0.19 \\
\hline & MTS4 & 0.09 & & & & $\sum^{5}$ & $\begin{array}{l}\text { MST } \\
\text { MTS4 }\end{array}$ & $\begin{array}{l}0.36 \\
0.85\end{array}$ & & & & & & & & & & & & & & & \\
\hline
\end{tabular}


united due to the similarity of its determined growth habit. The group III evidenced similarities of the genotypes NS 6700 IPRO, TMG 7262 RR, BMX Turbo RR, AS 3575 IPRO, AS 3610 IPRO, NS 5445IPRO and TEC 6029 IPRO. The group IV was formed by the genotypes DM 5958 IPRO, M5882 IPRO, NS5959 IPRO, M 5410 IPRO e M 6410 IPRO, group $V$ by the genotypes TMG 7062 IPRO, FPS Júpiter RR, BMX Alvo RR abd TMG 7063 IPRO and the group VI by the genotypes BMX Força RR, FPS Antares RR, BMX Elite IPRO, NA 5909 RG, BMX Magna RR abd BMX Tornado RR.

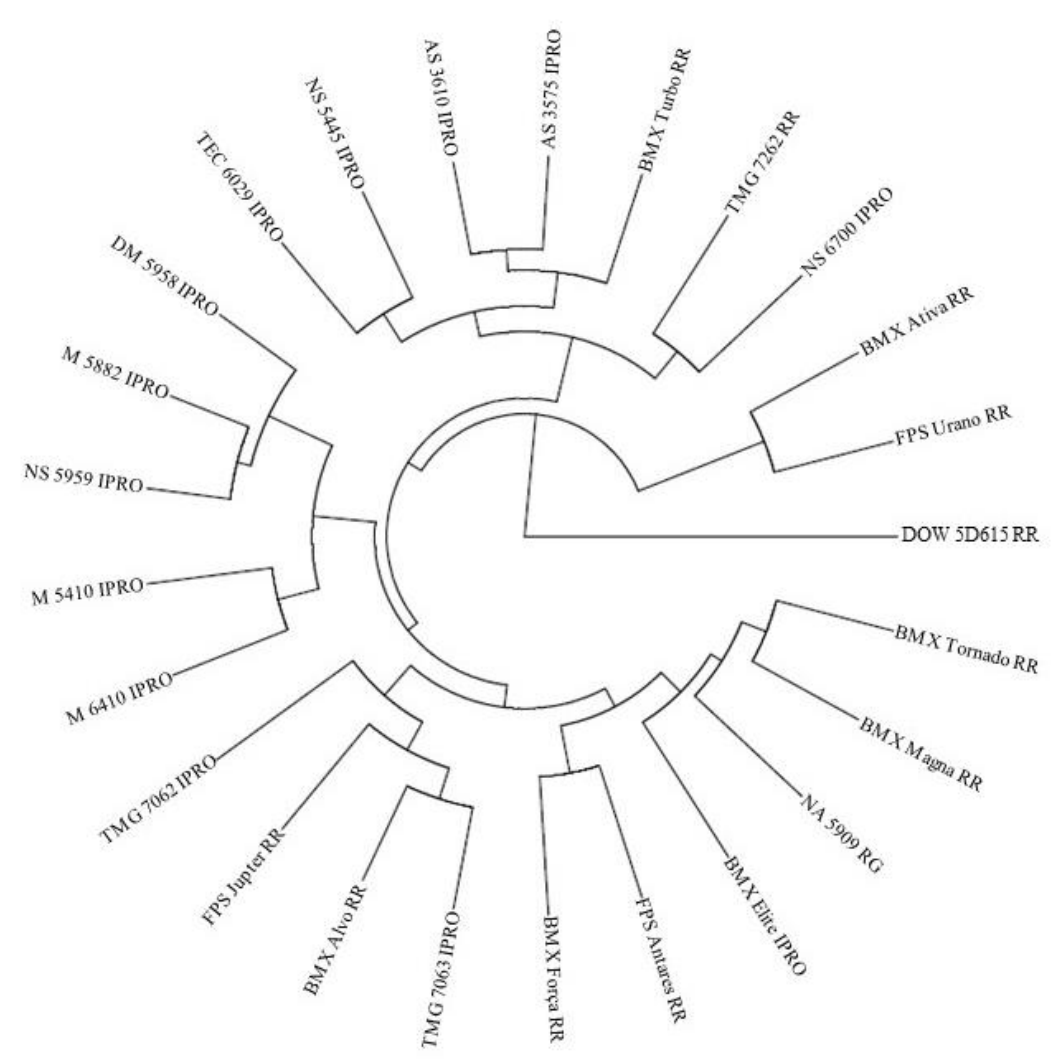

Figure 1. Dendrogram based on the genetic dissimilarity of 25 soybean genotypes using the Euclidiana mean standardized distance and grouping method UPGMA.

The characters MTS1, MTS2, MTS3, MTS4, TNS and PH correspond (Table 4) to the most polymorphic characters measured within the soybean genotypes, being revealed by the Singh method (1981) and can be defined as indispensable aspects to differentiate genotypes. The non-supervised learning obtained through the artificial neural networks using the mathematical model proposed by Kohonen (Figure 2), estimated 10 centroids that correspond to the mean dissimilarity profile within the used neurons. In this manner, the profile I corresponds to the genotypes BMX Magna RR and NA 5909 RG, being these gathered due to the similarity of the HFLI, NRNMS, NLMS, NLNMS, NRNP, NLP, NB and NSP.

The profile II gathered the genotype BMX Força RR, the profile II the genotype DOW 5D615 RR and the profile $V$ the genotype BMX Tornado RR. The genotypes FPS Urano RR, M 5410 IPRO, BMX Ativa RR and M 6410 IPRO were grouped in the centroid profile IV, due to the similarity of it with ten characters (HFLI, NLNMS, NRNB, NLB, NLNB, NL4S, TNL, MTS3, MTS4 and MSP.

The profile VI corresponded to the genotypes BMX Alvo RR, FPS Antares RR, BMX Elite IPRO and TMG 7062 IPRO.The profile VII was originated with the genotypes FPS Júpiter RR and TMG 7063 IPRO. The profile VIII corresponds to the genotypes DM 5958 IPRO, M 5882 IPRO and NS 5959 IPRO. The genotypes AS 3575 IPRO, NS5445 IPRO and TEC 6029 IPRO formed the profile IX. The profile $X$ correspond to the genotype AS3610 IPRO, NS6700 IPRO, TMG 7262 RR and BMX Turbo RR. The grouping of the genotypes in profiles corresponding to centroids allows identifying the multivariate selection of the genotypes, where, when identifying the ideal profile, the selection can be directed for all genotypes that form the centroid. This biometric tool allows lower errors in the classification and selection of which will be the similar or dissimilar genotypes. 


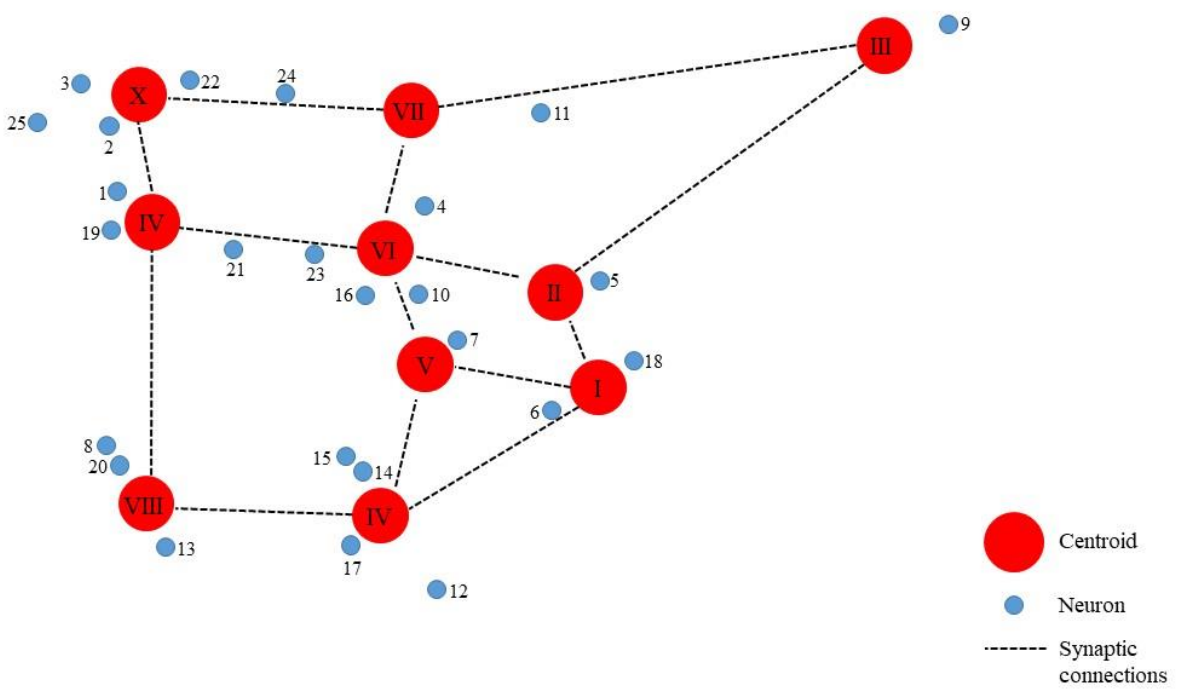

Figure 2. Artificial Neural Network with non-supervised computational learning, obtained through the Kohonen method, aiming to classify the 25 soybean genotypes using 26 agronomic attributes.

Table 4. Relative contribution of characters by Singh (1981).

\begin{tabular}{|c|c|c|}
\hline Variable & S.j & Relative Contribution\% \\
\hline${ }^{*} \mathrm{AP}$ & 192538.79 & 9.31 \\
\hline IPL & 20089.40 & 0.98 \\
\hline NNIHP & 717.98 & 0.03 \\
\hline NNRHP & 3038.31 & 0.15 \\
\hline NLHP & 26322.67 & 1.27 \\
\hline NLNHP & 135.08 & 0.01 \\
\hline NR & 788.50 & 0.04 \\
\hline NRNB & 24782.89 & 1.20 \\
\hline NLR & 72178.45 & 3.49 \\
\hline NLNR & 46.67 & 0.00 \\
\hline $\mathrm{CR}$ & 58809.78 & 2.84 \\
\hline NL1S & 2654.50 & 0.13 \\
\hline NL2S & 34183.46 & 1.65 \\
\hline NL3S & 26126.08 & 1.26 \\
\hline NL4S & 38.13 & 0.00 \\
\hline NTL & 106167.83 & 5.14 \\
\hline NTS & 314437.60 & 15.21 \\
\hline MS1 & 38.95 & 0.00 \\
\hline MS2 & 1576.04 & 0.02 \\
\hline MS3 & 5924.50 & 0.29 \\
\hline MS4 & 9.66 & 0.00 \\
\hline MST & 12241.03 & 0.60 \\
\hline MMS1 & 316140.92 & 15.29 \\
\hline MMS2 & 296234.79 & 14.33 \\
\hline MMS3 & 293957.70 & 14.22 \\
\hline MMS4 & 258257.68 & 12.49 \\
\hline
\end{tabular}

*Plant height $(\mathrm{PH}, \mathrm{cm})$, height of the first legume insertion (HFLI, $\mathrm{cm})$, number of nodes in the main stem (NNMS, units), number of reproductive nodes in the main stem (NRNMS, units), number of legumes in the main stem (NLMS, unit), number of legumes per node in the main stem (NLNMS, unit), number of branches (NB, unit), number of legumes per branch (NLB, unit), number of legumes per node in the branches (NLNB, unit), branches length (BL, $\mathrm{cm}$ ), number of reproductive nodes in the branch (NRNB, unit), number of legumes containing one seed (NL1S, unit), two seeds (NL2S), three seeds (NL3S, unit) and four seeds (NL4S, unit), total number of legumes per plant (TNL, unit), total number of seeds per plant (TNS, unit), mass of seeds from legumes with one, two, three and four seeds (MS1, MS2, MS3 and MS4), mass of seeds per plant (MSP, grams) and mass of thousand seeds stratified to the magnitude of seeds per legume (MTS1, MTS2, MTS3 and MTS4, grams). 


\section{CONCLUSIONS}

The Region of Alto Jacuí express the agronomic performance of the genotypes presents superior seed yield per plant through the elevated magnitude of reproductive nodes, legumes and seeds per plant.

The plant height of the soybean is positively associated with the number of total nodes and reproductive nodes in the main stem and branches, where they are directly linked with the soybean productive potential.

The most polymorphic characters correspond to the number and mass of thousand seeds, being possible to differentiate in a multivariate way the soybean genotypes though the similarity profiles.

\section{REFERENCES}

Balbinot-Junior, A. A., Procópio, S. O., Debiasi, H., Franchini, J. C., \& Panison, F. (2015). Semeadura cruzada em cultivares de soja com tipo de crescimento determinado. Semina: Ciencias Agrarias, 36(3), 12151225. https://doi.org/10.5433/1679-0359.2015v36n3p1215

Carvalho, I. R., Nardino, M., Demari, G. H., Bahry, C. A., Szareski, V. J., Pelissari, G., ... de Souza, V. Q. (2016). $\mathrm{Bi}$-segmented regression, factor analysis and $\mathrm{AMMI}$ applied to the analysis of adaptability and stability of soybean. Australian Journal of Crop Science, 10(10), 1410-1416. https://doi.org/10.21475/ajcs.2016.10.10.pne63

Carvalho, I. R., Nardino, M., Demari, G. H., Szareski, V. J., Follmann, D. N., Pelegrin, A. J., Ferrari, M., Olivoto, T., Barbosa, M. H., Oliveira, A. C., Maia, L. C., \& Souza, V. . Q. (2017). Relations among phenotypic traits of soybean pods and growth habit. African Journal of Agricultural Research, 12(6), 450-458. https://doi.org/10.5897/ajar2016.11660

Carvalho, I. R., Szareski, V. J., Demari, G. H., Barbosa, M. H., Conte, G. G., Lima, L. F. S., ... Pedó, T. (2018). Artificial Neural Network and Multivariate Models Applied to Morphological Traits and Seeds of Common Beans Genotypes. Journal of Agricultural Science, 10(11), 572. https://doi.org/10.5539/jas.v10n11p572

Carvalho, I. R., Nardino, M., \& Souza, V. Q. (2017). Melhoramento e Cultivo da Soja. 1ㅇ ed. Porto Alegre: Cidadela. v. 366p

Cavalett, O., \& Ortega, E. (2010). Integrated environmental assessment of biodiesel production from soybean in Brazil. Journal of Cleaner Production, 18(1), 55-70. https://doi.org/10.1016/j.jclepro.2009.09.008

CONAB - Companhia Nacional de Abastecimento. (2018). Série histórica: soja. Brasília, DF: CONAB. Retrieved from https://www.conab.gov.br/conabweb/download/safra/SojaSerieHist.xls

Cruz, C. D. (2014). Modelos biométricos aplicados ao melhoramento genético (3rd ed.). Viçosa, MG: Editora UFV.

Bruin, J. L., \& Pedersen, P. (2008). Effect of row spacing and seeding rate on soybean yield. Agronomy Journal, 100(3), 704-710. https://doi.org/10.2134/agronj2007.0106

Dueñas, M., Hernández, T., Robredo, S., Lamparski, G., Estrella, I., \& Muñoz, R. (2012). Bioactive Phenolic Compounds of Soybean (Glycine max cv. Merit): Modifications by Different Microbiological Fermentations. Polish Journal of Food and Nutrition Sciences, 62(4), 241-250. https://doi.org/10.2478/v10222-012-0060-x

EMBRAPA - Empresa Brasileira de Pesquisa Agropecuária. (2014). Tecnologia de produção de Soja - Região Central do Brasil 2014. Londrina, PR: EMBRAPA SOJA. Retrieved from https://ainfo.cnptia.embrapa.br/digital/bitstream/item/95489/1/SP-16-online

Komori, E., Hamawaki, O. T., Souza, M. P., \& Shigihara, D. (2004). Influência da época de semeadura e população de plantas sobre as características agronômicas da cultura da soja. Bioscience Journal, 20(3), 13-19. 
Sediyama, T. (2016). Produtividade da Soja,. Londrina, PR: Editora Mecenas.

Singh, D. (1981). The relative importance of characters affecting genetic divergence. Indian Journal of Genetics and Plant Breeding, 41(2), 237-245. Retrieved from http://www.indianjournals.com/ijor. aspx?target=ijor:ijgpb\&volume $=41 \&$ issue $=2 \&$ article $=010 \&$ type $=$ pdf

Streck, E. V., Kampf, N., Dalmolin, R. S. D., Klamt, E., Nascimento, P. C., Schneider, E., \& Pinto, L. F. S. (2008). Solos do Rio Grande do Sul (2nd ed.). Porto Alegre, RS: EMATER-RS.

Szareski, V. J., Souza, V. Q., Carvalho, I. R., Nardino, M., Follmann, D. N. Demari, G. H., Ferrari, M., \& Olivoto, T. (2015). Ambiente de cultivo e seus efeitos aos caracteres morfológicos e bromatológicos da soja. Revista Brasileira de Agropecuária Sustentável, 5(2), 79-88.

Szareski, V. J., Carvalho, I. R., Kehl, K., Levien, A. M., da Rosa, T. C., Barbosa, M. H., ... Aumonde, T. Z. (2018). Phenotypic and predicted genetic approaches for genotype ranking of wheat seed yield in Brazil. Genetics and Molecular Research, 17(3), 1-13. https://doi.org/10.4238/gmr18026

Thompson, N. M., Larson, J. A., Lambert, D. M., Roberts, R. K., Mengistu, A., Bellaloui, N., \& Walker, E. R. (2015). Mid-south soybean yield and net return as affected by plant population and row spacing. Agronomy Journal, 107(3), 979-989. https://doi.org/10.2134/agronj14.0453

Vasconcelos, E. S., Cruz, C. D., Bhering, L. L., \& Resende-Júnior, M. F. R. (2007). Método alternativo para análise de agrupamento. Pesquisa Agropecuária Brasileira, 42(10), 1421-1428. https://doi.org/10.1590/s0100-204×2007001000008

Received: January 20, 2021.

Accepted: March 6, 2021.

Published: March 31, 2021.

English by: Giordano Gelain Conte 